\title{
Erratum to: Metal- and Polymer-Matrix Composites: Functional Lightweight Materials for High-Performance Structures
}

\author{
NIKHIL GUPTA ${ }^{1,3}$ and MURALIDHARAN PARAMSOTHY ${ }^{2}$ \\ 1.-Composite Materials and Mechanics Laboratory, Mechanical and Aerospace Engineering \\ Department, Polytechnic School of Engineering, New York University, Brooklyn, NY 11201, \\ USA. 2.-Department of Mechanical Engineering, National University of Singapore, 9 Engi- \\ neering Drive 1, Singapore 117576, Singapore. 3.-e-mail: ngupta@nyu.edu
}

\section{Erratum to: JOM, Vol. 66, No. 6, 2014 DOI 10.1007/s11837-014-0969-0}

Reference 2 incorrectly listed one of the authors' names. The correct information for Reference 2 is:

2. A.D. Moghadam, B.F. Schultz, J.B. Ferguson, E. Omrani, P.K. Rohatgi, and N. Gupta, JOM 66 (2014). doi:10.1007/s11837-014-0948-5. 